\title{
Objective Evaluation of Therapeutic Effects of ADHD Medication Using a Smart Watch: A Pilot Study
}

\author{
Chen-Sen Ouyang ${ }^{1}$, Rei-Cheng Yang ${ }^{2}$, Ching-Tai Chiang ${ }^{3}$, Rong-Ching $\mathrm{Wu}^{4}$ and \\ Lung-Chang Lin 2,5,* \\ 1 Department of Information Engineering, I-Shou University, Kaohsiung City 84001, Taiwan; \\ ouyangcs@isu.edu.tw \\ 2 Departments of Pediatrics, Kaohsiung Medical University Hospital, Kaohsiung Medical University, \\ Kaohsiung City 80756, Taiwan; rechya@kmu.edu.tw \\ 3 Department of Computer and Communication, National Pingtung University, Pingtung City 900392, Taiwan; \\ cctai@mail.nptu.edu.tw \\ 4 Department of Electrical Engineering, I-Shou University, Kaohsiung City 84001, Taiwan; rcwu@isu.edu.tw \\ 5 Department of Pediatrics, School of Medicine, College of Medicine, Kaohsiung Medical University, \\ Kaohsiung City 80708, Taiwan \\ * Correspondence: lclin@kmu.edu.tw; Tel.: +886-7-312-1101 (ext. 6509); Fax: +886-7-321-3931
}

Received: 4 August 2020; Accepted: 25 August 2020; Published: 27 August 2020

\begin{abstract}
Attention-deficit hyperactivity disorder (ADHD) is the most common neurobehavioral disorder in schoolchildren. Several methods are used to evaluate ADHD therapeutic effects, including the Swanson, Nolan, and Pelham (SNAP) questionnaire, the Vanderbilt ADHD Diagnostic Rating Scale, and the visual analog scale. However, these scales are subjective. In this study, we employed an objective method to evaluate the aforementioned therapeutic effects. Ten patients (nine boys and one girl) with ADHD were enrolled. An accelerometer was embedded in a smart watch to record the movements of patients with ADHD. The variance values of the accelerometer before and after one month of medication (methylphenidate) use were compared. The results demonstrated that the variance values along the $y$ - and $z$-axes of the accelerometers significantly decreased after one month of methylphenidate use. Before and after one month of methylphenidate use, the variance values were $4.4227 \pm 2.1723$ and $2.3214 \pm 0.6475(p=0.0119)$ on the $y$-axis, and $4.0933 \pm 1.5720$ and $2.4091 \pm 0.8141$ $(p=0.0140)$ on the $z$-axis, respectively. In addition, the correlation was moderate-to-strong between the SNAP hyperactivity subscale and variance along the $y$-axis. Thus, a smart watch with an accelerometer inside is potentially an objective and useful method for evaluating the therapeutic effects of ADHD medications.
\end{abstract}

Keywords: attention-deficit hyperactivity disorder; variance; smart watch; accelerometer; Swanson, Nolan, and Pelham questionnaire

\section{Introduction}

Attention-deficit hyperactivity disorder (ADHD) is the most common neurobehavioral disorder in schoolchildren; its prevalence in the United States ranges from $2 \%$ to $18 \%$ in this age group [1]. If not treated, ADHD may not only affect the patients' functionality in childhood but also cause social and educational problems in later periods of their lives. Therefore, ADHD diagnosis and treatment are crucial in its early stages [2]. ADHD treatment may consist of drug therapy, behavioral therapy, or their combination. According to neurochemical evidence for ADHD, drug therapy is considered more effective than behavioral therapy [3]. Although stimulants are widely used for ADHD drug therapy, approximately $20 \%$ of children do not respond to the treatment [4]. There are several methods for evaluating the therapeutic effects of ADHD medication, including the Swanson, Nolan, and Pelham 
(SNAP) questionnaire [5], the Vanderbilt ADHD Diagnostic Rating Scale [6], and visual analog scales [7]. However, these rating scales are scored by parents or teachers of the patients, and this can lead to subjective bias during evaluation. Therefore, an objective method to measure these therapeutic effects is essential for monitoring the treatment effects of ADHD.

Currently, sensor technology has developed, to the point where tiny wireless sensors, as small as a watch, can record data for long periods. Devices with such sensors have been used in the research of many medical conditions, such as osteoarthritis, cerebral palsy, Parkinson disease, and stroke [8-11]. Increased activity is characteristic of patients with ADHD compared to those without ADHD [12,13]. Furthermore, two studies have used an accelerometer as an objective tool for ADHD diagnosis [14,15]. In addition, in two studies, a gyroscope combined with an accelerometer was used to distinguish the results of patients with ADHD from those without ADHD for various activities during a visit to a psychiatric consultancy [16] and when performing nine motor tasks [17]. However, the use of accelerometer measurements to evaluate therapeutic effects of ADHD medication is lacking. Moreover, our unpublished data demonstrated that the variance values of accelerometers in patients with ADHD were significantly higher than those in individuals without ADHD. In this study, we evaluated the therapeutic effect of the ADHD medication, methylphenidate, by using a smart watch equipped with an accelerometer and then analyzing the movements of patients with ADHD.

\section{Patients and Methods}

\subsection{Participants}

The study cohort comprised 10 children with ADHD, all of whom were examined by a pediatric neurologist or psychiatrist and were asked to wear the smart watches for recording. Children with a history of epilepsy, intellectual disability, drug abuse, head injury, or psychotic disorders were excluded. ADHD diagnosis was made according to the Diagnostic and Statistical Manual of Mental Disorders (DSM)-5 criteria, and the Swanson, Nolan, and Pelham Teacher and Parent Rating Scale (SNAP-IV) was used to evaluate ADHD severity. The 26 items of SNAP-IV include the 18 ADHD symptoms ( 9 for inattentiveness and 9 for hyperactivity/impulsiveness) and 8 oppositional defiant disorder symptoms specified in the DSM-IV. Items are rated on a four-point scale from 0 (not at all) to 3 (very much). ADHD has three subtypes, diagnoses of which are made depending on symptoms at presentation: inattentive (ADHD-I; inattentive symptoms and few or no hyperactive symptoms), hyperactive/impulsive (ADHD-H; hyperactive or impulsive symptoms and few or no inattentive symptoms), or combined (ADHD-C; both inattentive and hyperactive symptoms). Written informed consent was obtained from a family member or legal guardian of each participant. This study was approved by the Institutional Review Board of Kaohsiung Medical University Hospital (KMUIRB-SV(II)-20170015).

\subsection{Accelerometer Recordings}

An accelerometer embedded in a smart watch was used to record linear motion. Patients were asked to wear the watches on their nondominant wrist during the same class period before and after 1 month of methylphenidate use in this study. All patients started with methylphenidate $10 \mathrm{mg}$ per day for one month. They took medication only on weekdays and breaks from medication on weekends. Before methylphenidate use, patients with ADHD were recorded for $2 \mathrm{~h}$ per day for 3 consecutive days. After 1 month of methylphenidate use, they were recorded for $2 \mathrm{~h}$ per day for 2 consecutive days. The recording period started from one hour after medication in the morning, and the time point was the same for baseline and after 1 month on treatment. The class teacher recorded patients' activities during the study period. 


\subsection{Features Extraction}

Let $S$ be the signal matrix of an accelerometer recording of a subject:

$$
\boldsymbol{S}=\left[\begin{array}{c}
\boldsymbol{s}_{x} \\
\boldsymbol{s}_{y} \\
\boldsymbol{s}_{z}
\end{array}\right]=\left[\begin{array}{c}
s_{x 1}, s_{x 2}, \ldots, s_{x N} \\
s_{y 1}, s_{y 2}, \ldots, s_{y N} \\
s_{z 1}, s_{z 2}, \ldots, s_{z N}
\end{array}\right],
$$

where $s_{x}, s_{y}$, and $s_{z}$ are the signal sequences corresponding to the $x-, y-$ and $z$-axes, respectively, and $N$ the number of samples. To characterize the local variation of each signal sequence in the time domain, variance was calculated using a sliding window approach. Variance is a measure of the "spread" of a probability distribution of the signal subsequence. The signal sequence $s=\left[s_{1}, s_{2}, \ldots, s_{N}\right]$ was divided into a set of $K=N / W$ nonoverlapping subsequences:

$$
\left\{s_{1}^{\prime}, s_{2}^{\prime}, \ldots, s_{K}^{\prime}\right\}=\left\{\left[s_{1}, s_{2}, \ldots, s_{W}\right],\left[s_{W+1}, s_{W+2}, \ldots, s_{2 W}\right], \ldots,\left[s_{(K-1) W+1}, s_{(K-1) W+2}, \ldots, s_{K W}\right]\right\},
$$

where $s_{k}^{\prime}=\left[s_{(k-1) W+1}, s_{(k-1) W+2}, \ldots, s_{k W}\right]$ denotes the $k$ th subsequence of signal sequence $s$. To estimate the population variance of each subsequence $s_{k^{\prime}}^{\prime}$ sample variance was calculated as

$$
f_{s_{k}^{\prime}}^{v a r}=\frac{1}{W-1} \sum_{i=1}^{W}\left(s_{(k-1) W+i}-f_{s_{k}^{\prime}}^{a v g}\right)^{2}
$$

where $f_{s_{k}^{\prime}}^{a v g}$ is the corresponding sample average of $s_{k^{\prime}}^{\prime}$ calculated by

$$
f_{s_{k}^{\prime}}^{a v g}=\frac{1}{W-1} \sum_{i=1}^{W} s_{(k-1) W+i}
$$

After variance values of all subsequences were calculated, the corresponding average was calculated for estimating the expected variance of the signal sequence $s$ as follows:

$$
\overline{f_{s}^{v a r}}=\frac{1}{K} \sum_{i=1}^{W} f_{s_{k}^{\prime}}^{v a r}
$$

Therefore, three expected variance values, $\overline{f_{s_{x}}^{v a r}}, \overline{f_{s_{y}}^{v a r}}$, and $\overline{f_{s_{z}}^{v a r}}$, were obtained from the signal sequences, $s_{x}, s_{y}$, and $s_{z}$, respectively. Finally, three variance features were employed to characterize the accelerometer recording of each subject.

\section{Statistical Analysis}

All statistical analyses were conducted using SAS (version 9.3; SAS Institute Inc., Cary, NC, USA). Data were presented as means \pm standard deviations. The effects of ADHD methylphenidate before and after treatment were compared using a paired $t$ test, and because the accelerometer had three features, to avoid multiple comparisons on inflation of type I errors, we applied the Bonferroni adjustment, in which $p<0.05 / 3=0.0167$ was considered statistically significant. Pearson's correlation coefficient was used to calculate the correlation between decreases in SNAP scores and variance values of the accelerometer.

\section{Results}

Here, we enrolled 10 patients (nine boys and one girl; mean (standard deviation) age was seven years and five months (one year and three months)). Eight boys had ADHD-C, and one boy and the girl had ADHD-I. The SNAP scores obtained from the teacher before and after one month of 
methylphenidate use were $40.90 \pm 9.27$, and $21.13 \pm 12.16$, respectively (average percent decrease $=$ $48.35 \%$; Table 1).

Table 1. Demographic data of patients with attention-deficit hyperactivity disorder (ADHD).

\begin{tabular}{ccccccc}
\hline $\begin{array}{c}\text { Patient } \\
\text { Number }\end{array}$ & Sex & Age & $\begin{array}{c}\text { SNAP Score before } \\
\text { Medication }\end{array}$ & $\begin{array}{c}\text { SNAP Score after } \\
\text { Medication }\end{array}$ & $\begin{array}{c}\text { Reduction } \\
\text { Percentage }\end{array}$ & Subtype \\
\hline Patient 1 & M & $6 y 5 \mathrm{~m}$ & 60 & NA & NA & Combined type \\
Patient 2 & M & $7 \mathrm{y} 8 \mathrm{~m}$ & 42 & 38 & $9.5 \%$ & Combined type \\
Patient 3 & $\mathrm{M}$ & $7 \mathrm{y} 10 \mathrm{~m}$ & 38 & $\mathrm{NA}$ & $\mathrm{NA}$ & Combined type \\
Patient 4 & $\mathrm{M}$ & $6 \mathrm{y} 5 \mathrm{~m}$ & 39 & 35 & $10.3 \%$ & Combined type \\
Patient 5 & $\mathrm{M}$ & $6 \mathrm{y} 11 \mathrm{~m}$ & 34 & 9 & $67.6 \%$ & Combined type \\
Patient 6 & $\mathrm{M}$ & $7 \mathrm{y}$ & 51 & 32 & $82.4 \%$ & Combined type \\
Patient 7 & $\mathrm{M}$ & $7 \mathrm{y} 9 \mathrm{~m}$ & 43 & 13 & $25.6 \%$ & Combined type \\
Patient 8 & $\mathrm{M}$ & $10 \mathrm{y} 4 \mathrm{~m}$ & 26 & 21 & $50.0 \%$ & Inattention type \\
Patient 9 & $\mathrm{M}$ & $5 \mathrm{y} 11 \mathrm{~m}$ & 37 & 10 & $73.2 \%$ & Combined type \\
Patient 10 & $\mathrm{F}$ & $7 \mathrm{y} 8 \mathrm{~m}$ & 39 & & & Inattention type \\
\hline
\end{tabular}

The variance values along the $y$ - and $z$-axes of the accelerometer in patients with attention-deficit hyperactivity disorder (ADHD) demonstrated significant decrease after one month of methylphenidate use. Before and after one month of methylphenidate use, the variance values were $4.4227 \pm 2.1723$ and $2.3214 \pm 0.6475(p=0.0119)$ on the $y$-axis, and $4.0933 \pm 1.5720$ and $2.4091 \pm 0.8141(p=0.0140)$ on the $z$-axis, respectively (Table 2). Figure 1 displays significantly higher variance values of accelerometer measurements before methylphenidate use than after one month of methylphenidate use. In some patients, the decreases in SNAP scores obtained from teachers demonstrated difference compared with the decreases in variance values (Figure 2). The correlation between the decrease in SNAP scores and decrease in variance values along the three axes before and after one month of methylphenidate use was not significant.

Table 2. Comparison of variance values across three axes before and after treatment.

\begin{tabular}{cccc}
\hline & Before Treatment & After Treatment & $p$ Value \\
\hline Variance X & $4.3911 \pm 2.4874$ & $2.1214 \pm 0.9058$ & 0.0232 \\
Variance Y & $4.4227 \pm 2.1723$ & $2.3214 \pm 0.6475$ & $0.0119 *$ \\
Variance Z & $4.0933 \pm 1.5720$ & $2.4091 \pm 0.8141$ & $0.0140 *$ \\
\hline \multicolumn{4}{c}{$* p<0.05 / 3=0.0167}$.
\end{tabular}

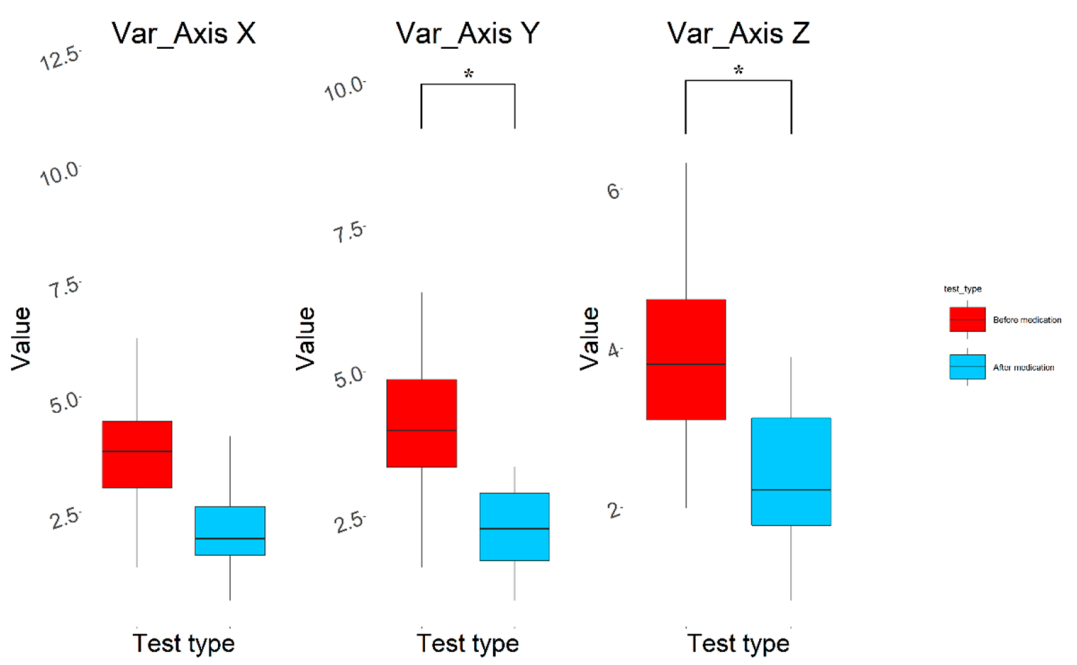

Figure 1. Reductions in variance values of accelerometer along three axes. Significant reductions of variance values of accelerometer along the $y$ - and $z$-axis after 1 month of medication use in patients with ADHD. ${ }^{*} p<0.05 / 3=0.0167$. 


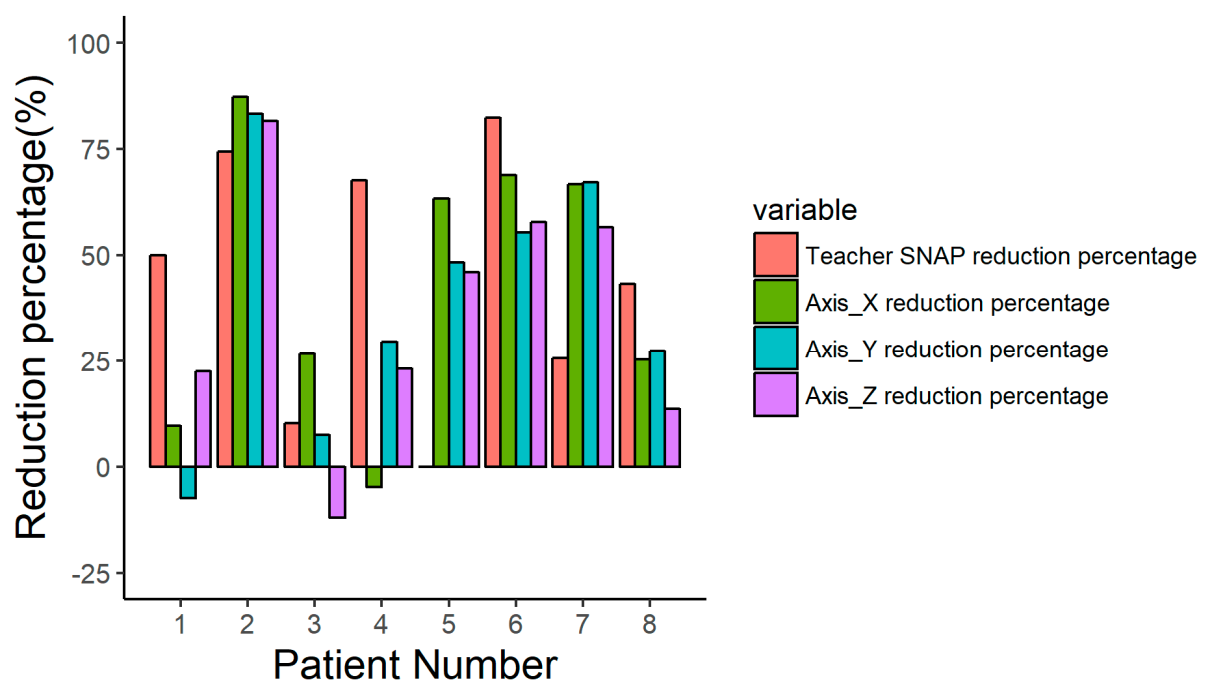

Figure 2. Correlation between decreased Swanson, Nolan, and Pelham (SNAP) questionnaire scores and reduction in variance values. Some patients with ADHD exhibited discrepancy between decreased SNAP scores and reduced accelerometer variance values of along the three axes.

We also calculated the correlation coefficient between ADHD SNAP subscales (inattentive, hyperactive, and oppositional defiant) and three-axis variance reduction values after one month of methylphenidate use. The results revealed the highest correlation coefficient between SNAP hyperactive subscale and the variance value along the $y$-axis (Table 3) (correlation coefficient $=0.6053$, indicating moderate-to-strong correlation between these two parameters) [18].

Table 3. Correlation coefficient between reductions of SNAP subscales and variance values across three axes.

\begin{tabular}{cccc}
\hline & $\begin{array}{c}\text { Axis_X Var Reduction } \\
\text { Percentage }\end{array}$ & $\begin{array}{c}\text { Axis_Y Var Reduction } \\
\text { Percentage }\end{array}$ & $\begin{array}{c}\text { Axis_Z Var Reduction } \\
\text { Percentage }\end{array}$ \\
\hline $\begin{array}{c}\text { Teacher SNAP (I) } \\
\text { Reduction Percentage } \\
\text { Teacher SNAP (H) }\end{array}$ & -0.0227 & 0.0917 & 0.3565 \\
$\begin{array}{c}\text { Reduction Percentage } \\
\text { Teacher SNAP (O) } \\
\text { Reduction Percentage }\end{array}$ & 0.2881 & 0.6053 & 0.4605 \\
\hline
\end{tabular}

(I): inattentive; $(\mathrm{H})$ : hyperactive; $(\mathrm{O})$ : oppositional defiant.

\section{Discussion}

In this study, we found that the variance values along the $y$ - and $z$-axes of the accelerometer significantly decreased in patients with ADHD after the use of methylphenidate, an ADHD medication. Thus, the variance value may be a useful and objective marker for evaluating therapeutic effects of ADHD medication use in patients with ADHD.

The SNAP questionnaire were originally developed to assess ADHD symptoms according to the DSM-III $[19,20]$. Although several studies have demonstrated that the SNAP score has high validity and reliability [21-23], one study found that interrater agreement between parents and teachers is poor [5]. In addition, the parents' ratings of inattention and hyperactivity/impulsivity are good predictors for research but not for clinical diagnosis. Regarding teacher ratings, only hyperactivity/impulsivity scores are good predictors for research and clinician diagnosis [22]. The discrepancies in the SNAP scores by parents and teachers for patients with ADHD can lead to diagnostic uncertainty. We used a smart watch equipped with an accelerometer to record the activity of patients with ADHD and noted 
significant decreases in variance values of accelerometer recordings. This method is recommended as an objective and convenient tool for evaluating the therapeutic effects of ADHD medications.

Electronic devices have been used to detect motor function in several medical conditions. Ellis et al. used smartphones to detect gait variability in patients with Parkinson's disease (PD) and found increased gait variability in patients with PD compared with healthy controls [24]. Galán-Mercant et al. analyzed the differences in variance of performance in the Extended Timed Up and Go test in frail and nonfrail elderly people by using smartphones. The authors reported that accelerometry values for the frail elderly people were lower than those for the nonfrail elderly people [25]. In patients with idiopathic normal pressure hydrocephalus (iNPH), a body-worn gyroscopic system was used to detect gait and postural stability. The results demonstrated that the patients with iNPH had significantly higher trunk sway compared with healthy elderly patients, specifically in standing tasks [26]. Here, we used an accelerometer to evaluate the therapeutic effects of an ADHD medication, methylphenidate, in patients with ADHD and noted that the variance values along the $y$ - and $z$-axes significantly decreased after one month of methylphenidate use. Accordingly, a smart watch equipped with an accelerometer is an effective alternative method for evaluating the treatment effects of ADHD medications.

Of the ADHD subtypes, the most prevalent are ADHD-C and ADHD-H (78.0-81.7\%), followed by ADHD-I (18.3-22.0\%) [27-29]. Here, 8 of 10 patients had ADHD-C, and therefore, most of the recruited patients demonstrated hyperactive symptoms. Accordingly, we noted a moderate-to-strong correlation between decreased SNAP hyperactive subscale scores and variance values of the $y$-axis of the accelerometer.

This study has some limitations. First, although the variance values of the accelerometer between before and after one month of methylphenidate in patients with ADHD differed significantly, the sample size was small. Second, we enrolled children with two different ADHD subtypes with limited number; thus, the results may not be generalizable to all ADHD subtypes. In the future, more patients with different subtypes will be enrolled to investigate the medication effects on three ADHD subtypes.

\section{Conclusions}

Most patients with ADHD have the ADHD-H or ADHD-C subtype. In the present study, the variance values of movement, calculated using an accelerometer, was used as an indicator for objective evaluation of the treatment effects of ADHD medication, such as methylphenidate. The results demonstrated that the variance values significantly decreased after one month of methylphenidate use, and the reduced variance values had a moderate-to-strong correlation with the hyperactive subscale of the SNAP questionnaire. Thus, the use of a smart watch equipped with an accelerometer is an objective and useful method for evaluating the therapeutic effects of ADHD medication, particularly in patients with ADHD-H and ADHD-C.

Author Contributions: Conceptualization, L.-C.L., R.-C.W. and R.-C.Y.; methodology, C.-S.O. and C.-T.C.; validation, C.-S.O.; investigation, C.-S.O. and R.-C.W.; writing-original draft preparation, L.-C.L.; writing-review and editing, L.-C.L., R.-C.W. and R.-C.Y. All authors have read and agreed to the published version of the manuscript.

Funding: This study was supported partly by a grant from the Kaohsiung Medical University Hospital (KMUH107-7R42), a research grant from the Changhua Christian Hospital and Kaohsiung Medical University Research Foundation (108-CCH-KMU-005), and grants from Ministry of Science and Technology, Taiwan (MOST 106-2314-B-037-080-MY2, MOST 107-2221-E-214-028, and MOST 108-2221-E-214-020).

Conflicts of Interest: None of the authors have potential conflicts of interest to be disclosed.

\section{References}

1. Berger, I. Diagnosis of attention deficit hyperactivity disorder: Much ado about something. Isr. Med. Assoc. J. 2011, 13, 571-574. [PubMed]

2. Aldemir, R.; Demirci, E.; Bayram, A.K.; Canpolat, M.; Ozmen, S.; Per, H.; Tokmakci, M. Evaluation of two types of drug treatment with qeeg in children with adhd. Transl. Neurosci. 2018, 9, 106-116. [CrossRef] 
3. Jensen, P.S. A 14-month randomized clinical trial of treatment strategies for attention-deficit/hyperactivity disorder. Arch. Gen. Psychiatry 1999, 56, 1073-1086.

4. Cornforth, C.; Sonuga-Barke, E.; Coghill, D. Stimulant drug effects on attention deficit/hyperactivity disorder: A review of the effects of age and sex of patients. Curr. Pharm. Des. 2010, 16, 2424-2433. [CrossRef] [PubMed]

5. Swanson, J.M.; Kraemer, H.C.; Hinshaw, S.P.; Arnold, L.E.; Conners, C.K.; Abikoff, H.B.; Clevenger, W.; Davies, M.; Elliott, G.R.; Greenhill, L.L.; et al. Clinical relevance of the primary findings of the mta: Success rates based on severity of adhd and odd symptoms at the end of treatment. J. Am. Acad. Child Adolesc. Psychiatry 2001, 40, 168-179. [CrossRef] [PubMed]

6. Wolraich, M.L.; Lambert, W.; Doffing, M.A.; Bickman, L.; Simmons, T.; Worley, K. Psychometric properties of the vanderbilt adhd diagnostic parent rating scale in a referred population. J. Pediatric Psychol. 2003, 28, 559-568. [CrossRef] [PubMed]

7. Woolsey, C.; Smoldon, J.; Devney, R. Initial development of an attention-deficit/hyperactivity disorder visual analog scale for rapid assessment of medication effects. J. Am. Assoc. Nurse Pract. 2019. [CrossRef] [PubMed]

8. Staab, W.; Hottowitz, R.; Sohns, C.; Sohns, J.M.; Gilbert, F.; Menke, J.; Niklas, A.; Lotz, J. Accelerometer and gyroscope based gait analysis using spectral analysis of patients with osteoarthritis of the knee. J. Phys. Ther. Sci. 2014, 26, 997-1002. [CrossRef]

9. Zollinger, M.; Degache, F.; Currat, G.; Pochon, L.; Peyrot, N.; Newman, C.J.; Malatesta, D. External mechanical work and pendular energy transduction of overground and treadmill walking in adolescents with unilateral cerebral palsy. Front. Physiol. 2016, 7, 121. [CrossRef]

10. Ossig, C.; Antonini, A.; Buhmann, C.; Classen, J.; Csoti, I.; Falkenburger, B.; Schwarz, M.; Winkler, J.; Storch, A. Wearable sensor-based objective assessment of motor symptoms in parkinson's disease. J. Neural. Transm. (Vienna) 2016, 123, 57-64. [CrossRef]

11. Capela, N.A.; Lemaire, E.D.; Baddour, N.; Rudolf, M.; Goljar, N.; Burger, H. Evaluation of a smartphone human activity recognition application with able-bodied and stroke participants. J. Neuroeng. Rehabil. 2016, 13, 5. [CrossRef] [PubMed]

12. Tseng, M.H.; Henderson, A.; Chow, S.M.; Yao, G. Relationship between motor proficiency, attention, impulse, and activity in children with adhd. Dev. Med. Child Neurol. 2004, 46, 381-388. [CrossRef] [PubMed]

13. Wood, A.C.; Asherson, P.; Rijsdijk, F.; Kuntsi, J. Is overactivity a core feature in adhd? Familial and receiver operating characteristic curve analysis of mechanically assessed activity level. J. Am. Acad. Child Adolesc. Psychiatry 2009, 48, 1023-1030. [CrossRef] [PubMed]

14. Martin-Martinez, D.; Casaseca-de-la-Higuera, P.; Alberola-Lopez, S.; Andres-de-Llano, J.; Lopez-Villalobos, J.A.; Ardura-Fernandez, J.; Alberola-Lopez, C. Nonlinear analysis of actigraphic signals for the assessment of the attention-deficit/hyperactivity disorder (adhd). Med. Eng. Phys. 2012, 34, 1317-1329. [CrossRef] [PubMed]

15. Kam, H.J.; Lee, K.; Cho, S.M.; Shin, Y.M.; Park, R.W. High-resolution actigraphic analysis of adhd: A wide range of movement variability observation in three school courses-A pilot study. Healthc. Inform. Res. 2011, 17, 29-37. [CrossRef] [PubMed]

16. O'Mahony, N.; Florentino-Liano, B.; Carballo, J.J.; Baca-Garcia, E.; Rodriguez, A.A. Objective diagnosis of adhd using imus. Med. Eng. Phys. 2014, 36, 922-926. [CrossRef]

17. Ricci, M.; Terribili, M.; Giannini, F.; Errico, V.; Pallotti, A.; Galasso, C.; Tomasello, L.; Sias, S.; Saggio, G. Wearable-based electronics to objectively support diagnosis of motor impairments in school-aged children. J. Biomech. 2018. [CrossRef]

18. Akoglu, H. User's guide to correlation coefficients. Turk. J. Emerg. Med. 2018, 18, 91-93. [CrossRef]

19. Spitzer, R.L.; Md, K.K.; Williams, J.B.W. Diagnostic and Statistical Manual of Mental Disorders, 3rd ed.; American Psychiatric Association: Washington, DC, USA, 1980.

20. Association, A.P. Diagnostic and statistical manual of mental disorders. BMC Med. 2013, 17, $133-137$.

21. Costa, D.S.; de Paula, J.J.; Malloy-Diniz, L.F.; Romano-Silva, M.A.; Miranda, D.M. Parent snap-iv rating of attention-deficit/hyperactivity disorder: Accuracy in a clinical sample of adhd, validity, and reliability in a brazilian sample. J. Pediatr. 2018. [CrossRef]

22. Hall, C.L.; Guo, B.; Valentine, A.Z.; Groom, M.J.; Daley, D.; Sayal, K.; Hollis, C. The validity of the snap-iv in children displaying adhd symptoms. Assessment 2019. [CrossRef] [PubMed] 
23. Gau, S.S.; Shang, C.Y.; Liu, S.K.; Lin, C.H.; Swanson, J.M.; Liu, Y.C.; Tu, C.L. Psychometric properties of the chinese version of the swanson, nolan, and pelham, version iv scale-Parent form. Int. J. Methods Psychiatr. Res. 2008, 17, 35-44. [CrossRef] [PubMed]

24. Ellis, R.J.; Ng, Y.S.; Zhu, S.; Tan, D.M.; Anderson, B.; Schlaug, G.; Wang, Y. A validated smartphone-based assessment of gait and gait variability in parkinson's disease. PLoS ONE 2015, 10, e0141694. [CrossRef]

25. Galan-Mercant, A.; Cuesta-Vargas, A.I. Differences in trunk accelerometry between frail and non-frail elderly persons in functional tasks. BMC Res. Notes 2014, 7, 100. [CrossRef]

26. Backlund, T.; Frankel, J.; Israelsson, H.; Malm, J.; Sundstrom, N. Trunk sway in idiopathic normal pressure hydrocephalus-quantitative assessment in clinical practice. Gait Posture 2017, 54, 62-70. [CrossRef] [PubMed]

27. Grunwald, J.; Schlarb, A.A. Relationship between subtypes and symptoms of adhd, insomnia, and nightmares in connection with quality of life in children. Neuropsychiatr. Dis. Treat. 2017, 13, 2341-2350. [CrossRef]

28. AlZaben, F.N.; Sehlo, M.G.; Alghamdi, W.A.; Tayeb, H.O.; Khalifa, D.A.; Mira, A.T.; Alshuaibi, A.M.; Alguthmi, M.A.; Derham, A.A.; Koenig, H.G. Prevalence of attention deficit hyperactivity disorder and comorbid psychiatric and behavioral problems among primary school students in western saudi arabia. Saudi Med. J. 2018, 39, 52-58. [CrossRef]

29. Salvi, V.; Migliarese, G.; Venturi, V.; Rossi, F.; Torriero, S.; Vigano, V.; Cerveri, G.; Mencacci, C. Adhd in adults: Clinical subtypes and associated characteristics. Riv. Psichiatr. 2019, 54, 84-89.

(C) 2020 by the authors. Licensee MDPI, Basel, Switzerland. This article is an open access article distributed under the terms and conditions of the Creative Commons Attribution (CC BY) license (http://creativecommons.org/licenses/by/4.0/). 